\title{
Surface Functionalization of Silica and Zirconia Sol-Gel Materials with Europium Complexes
}

\author{
Nina Danchova, Stoyan Gutzov*
}

Sofia University "St. Kliment Ohridski", Faculty of Chemistry and Pharmacy, Department of Physical Chemistry,

J. Bourchier Blvd. 1, 1164 Sofia, Bulgaria

*-sgutzov@chem.uni-sofia.bg

Keywords: silica, europium complexes, luminescence, sol-gel, zirconia

\begin{abstract}
The present contribution is focused on the relation preparation - structure - optical properties of hybrid silica and zirconia powders containing $\mathrm{Eu}(\mathrm{III})$ complexes: [ $\left.\mathrm{Eu}(\mathrm{ntac})_{3}\right][\mathrm{pphendcn}]$ and

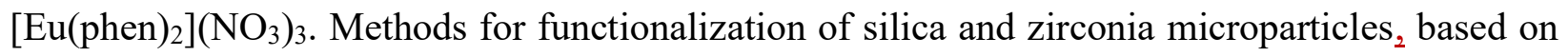
adsorption of 1,10-phenantroline and $\left[\mathrm{Eu}(\mathrm{ntac})_{3}\right]\left[\right.$ pphenden], and doping with $\left[\mathrm{Eu}(\mathrm{phen})_{2}\right]\left(\mathrm{NO}_{3}\right)_{3}$ nanoparticles are proposed to obtain of red emitting hybrid composites with quantum efficiency $20-50 \%$. The optical properties of rare earth ions incorporated in silica and zirconia composites are used to explore the site symmetry $\left(\mathrm{D}_{2}, \mathrm{C}_{2 \mathrm{v}}\right.$ or lower) of the $\mathrm{Eu}^{3+}$ optical centers in the hybrid composites. Quantum yields of the investigated sol-gel micropowders and quantification of their optical spectra are presented.
\end{abstract}




\section{Introduction}

Sol-gel materials functionalized with rare earth ions and their complexes display important optical properties like luminescence, coloration and energy transfer and give opportunity for wide technical applications as light sources, materials for UV - and IR energy conversion and optical sensors [1,2,3]. As a red emission source Eu(III) complexes with organic ligands are the most often used materials due to their pure, red emission with maxima at about $590 \mathrm{~nm}, 615 \mathrm{~nm}, 650 \mathrm{~nm}$ and $700 \mathrm{~nm}$ [1-4]. From materials science point of view sol-gel species functionalized with rare earth ions are hybrid materials as they contain an organic ligand or complex in an inorganic matrix. Solgel chemistry is the most utilized method for preparation of the inorganic matrixes because of the possibilities of low temperature preparation conditions, molecular level of doping and processing of powders, aerogels or monoliths [4].

Doping of ceramic matrixes /silica, zirconia, alumina, tin oxides/ with europium (III) complexes is a complicated process. If a classic case of sol-gel doping is used, the hybrid optical active specie, here an europium complex, is introduced in the silica containing sol $[6,8,9]$. Often, europium complexes used in the preparation of hybrid sol-gel composites decomposes during solgel process, leading to a low red emission intensity of the obtained sol-gel hybrid composites together with an additional blue or violet emission [6].

This paper deals with preparation strategies of silica and zirconia gels doped with europium complexes, avoiding decomposition of the europium complexes during sol-gel doping. We are presenting three methods for preparation of strong emitting zirconia or silica samples including: a) physical adsorption of $\left[\mathrm{Eu}(\mathrm{ntac})_{3}\right][\mathrm{pphenden}]$ on silica surface b) chemical adsorption of 1,10phenathroline on the surface of europium doped silica and c) incorporation of $\mathrm{Eu}(\text { phen })_{2}\left(\mathrm{NO}_{3}\right)_{3} \cdot \mathrm{nH}_{2} \mathrm{O}$ colloidal nanocrystals in zirconia sol-gel material.

Here, the following notation is used: [Eu(ntac) 3$][$ pphenden] containing 4,4,4-trifluoro-1(naphthalene-2-yl) butan-1,3-dione (Hntac) and pyrazino[2,3-f][1,10-phenathroline-2,3dicarbonitrile (pphenden) is a new europium complex, detailed described in $[5,6,7,8,9,10,11]$. The quantum efficiency of the solid complex is $10-15 \%$ [6-10]. $\mathrm{Eu}(\mathrm{phen})_{2}\left(\mathrm{NO}_{3}\right)_{3} \cdot \mathrm{nH}_{2} \mathrm{O}$, europium (III) diphenathroline nitrate, is a well-known solid luminescent complex, detailed described in the paper of Mirochnik et al [11]. The quantum efficiency of the solid complex is $35-40 \%$. The room temperature solubility of $\mathrm{Eu}(\mathrm{phen})_{2}\left(\mathrm{NO}_{3}\right)_{3} \cdot \mathrm{nH}_{2} \mathrm{O}$ in ethanol is $4.5 \cdot 10^{-5} \mathrm{~mol} / 1$, the solubility of $\left[\mathrm{Eu}(\text { ntac })_{3}\right][$ pphenden] is much lower. 


\section{Experimental}

The europium complexes $\left[\mathrm{Eu}(\mathrm{phen})_{2}\right]\left(\mathrm{NO}_{3}\right)_{3}$ and $\left[\mathrm{Eu}(\mathrm{ntac})_{3}\right][\mathrm{pphendcn}]$ were synthesized according procedures discussed in [8]. A SpectraPro 300i spectrophotometer was used for measurement of diffuse reflectance, excitation / luminescence spectra and quantum yield of powdered samples. As standard, the Lumogen T Rot GG from BASF with maximum wavelength of excitation at $350 \mathrm{~nm}$ and maximum wavelength of emission at $615 \mathrm{~nm}$ was chosen. The Quantum Yield (QY) of the investigated samples was determined using the comparison method. Emission spectra were integrated between 430 and $750 \mathrm{~nm}$ and excitation spectra between 235 and $430 \mathrm{~nm}$. The luminescence and reflectance measurements were used to estimate the QY (defined as the ratio of the number of photons emitted to the number of photons absorbed) of investigated samples. In this study, the presented luminescence spectra are mathematically threated as overlapping Gaussion curves to obtain relative intensities, peak number, peak maxima and half widths of each luminescence peak. The $\mathrm{Eu}$ - content in all samples prepared was checked using a ICP Ultima2 Horiba-Jobin Yvon unit.

Emission and excitation spectra with a higher resolution at about $1 \mathrm{~nm}$ were measured on a Varian Cary Eclipse fluorescence spectrophotometer with a self-made vertical sample holder, detailed described in [10]. To obtain the peak number in the region of each Stark multiplet second derivative luminescence spectra deconvolution has been applied. All peak maxima detected in this paper were in agreement with the electronic transition of $\mathrm{Eu}^{3+}$ ion [4].

To prepare silica and zirconia microparticles with an intense red emission, three physico chemical functionalization techniques, described below, were used.

\section{A) Surface functionalization of silica micro particles with [Eu(ntac) 3 ] [pphendcn] (physical functionalization)}

The preparation of hybrid silica micro composites includes the following basic steps:

1. Preparation of $\mathrm{SiO}_{2}$ matrix, using a classical base catalyzed sol-gel process, Danchova \& Gutzov (2013) [9].

2. Homogenization of the solid matrix in mortar to obtain silica micro particles in size 100$300 \mu \mathrm{m}$.

3. Impregnation of silica micro particles with solution of $0.0107 \mathrm{M}\left[\mathrm{Eu}(\mathrm{ntac})_{3}\right][\mathrm{pphenden}]$ in ethanol (48 $\mathrm{h}$ at room temperature). 


\section{B) Preparation of functionalized micro particles starting from $\mathrm{SiO}_{2}: \mathrm{Eu}$ (chemical functionalization)}

The preparation includes the following basic steps:

1. Synthesis of doped $\mathrm{SiO}_{2}: \mathrm{Eu}^{3+}$ sol-gel bulk materials with molar ratio $\mathrm{n}_{\mathrm{Eu}} / \mathrm{n}_{\mathrm{Si}}=0.05$ using the procedure of Danchova \& Gutzov (2013) [8].

2. Homogenization of silica gel in mortar to obtain $\mathrm{SiO}_{2}: \mathrm{Eu}^{3+}$ silica micro particles

3. Impregnation of doped $\mathrm{SiO}_{2}$ micro particles with ethanol solution of $1.1 \mathrm{M} 1,10$ phenanthroline $\left(48 \mathrm{~h}\right.$ at room temperature with molar ratio $\mathrm{n}_{\mathrm{Eu}} / \mathrm{n}_{\text {phen }}=9.4 \cdot 10^{-3}$, $\mathrm{n}_{\mathrm{Si}} / \mathrm{n}_{\text {phen }}=0.18$.

4. Washing the micropowders with absolute ethanol to remove the excess amount of ligand.

C) Incorporation of Eu(phen 2$)\left(\mathrm{NO}_{3}\right)_{3} \cdot x \mathrm{H}_{2} \mathrm{O}$ nanoparticles in to a zirconia sol, followed by gelation. [ [ $\left.\begin{array}{llll}5 & 6 & 7 & 8\end{array}\right]$

The preparation of hybrid silica micro composites includes the following basic steps:

1. Preparation of a stable zirconia sol, using acetic acid as a complex forming agent to prevent fast hydrolysis and gelation.

2. Preparation of $\mathrm{Eu}\left(\mathrm{phen}_{2}\right)\left(\mathrm{NO}_{3}\right)_{3} \cdot \mathrm{xH}_{2} \mathrm{O}$ following the procedure, described in our recent paper [12]

3. Addition of the fresh sol, containing $\mathrm{Eu}\left(\mathrm{phen}_{2}\right)\left(\mathrm{NO}_{3}\right)_{3} \cdot \mathrm{xH}_{2} \mathrm{O}$ nanoparticles to the $\mathrm{Zr}(\mathrm{IV})$ sol and gelation of the system.

\section{Experimental results and discussion}

In Fig. 1. luminescence and excitation spectra of solid $\mathrm{SiO}_{2}$ :[Eu(ntac) $\left.)_{3}\right][\mathrm{pphenden}]$, prepared using the method of physical adsorption are presented. The relative intensity of the $\mathrm{Eu}^{3+}$ ${ }^{5} \mathrm{D}_{0} \rightarrow{ }^{7} \mathrm{~F}_{2}$ transition is about $83-85 \%$. In the terms $\mathrm{Eu}^{3+}$ site symmetry / spectra correlation, the most probable site symmetry in $\mathrm{SiO}_{2}$ : $\left[\mathrm{Eu}(\mathrm{ntac})_{3}\right]\left[\right.$ pphenden] is $\mathrm{D}_{2}$ because of the lack of intensity in the region of the ${ }^{5} \mathrm{D}_{0} \rightarrow{ }^{7} \mathrm{~F}_{0}$ emission transition of the $\mathrm{Eu}^{3+}$ ion [6]. It is interesting that the site symmetry of the europium ion is increased as a result of the physical adsorption, while the $\mathrm{Eu}^{3+}$ 
site symmetry in solution or in solid $\left[\mathrm{Eu}(\mathrm{ntac})_{3}\right][\mathrm{pphenden}]$ is $\mathrm{C}_{2}$ or lower. In the spectra of solid $\left[\mathrm{Eu}(\mathrm{ntac})_{3}\right][\mathrm{pphendcn}]$ a relatively intense emission line in the region of the ${ }^{5} \mathrm{D}_{0} \rightarrow{ }^{7} \mathrm{~F}_{0}$ emission transition of the $\mathrm{Eu}^{3+}$ ion together with three lines in the region of the ${ }^{5} \mathrm{D}_{0} \rightarrow{ }^{7} \mathrm{~F}_{1}$ and five lines in the ${ }^{5} \mathrm{D}_{0} \rightarrow{ }^{7} \mathrm{~F}_{2}$ transition which reveal the site-symmetry of the activator ion [6]. That means that during physical adsorption the complex structure is changed most probably because of the occurrence of surface interactions.

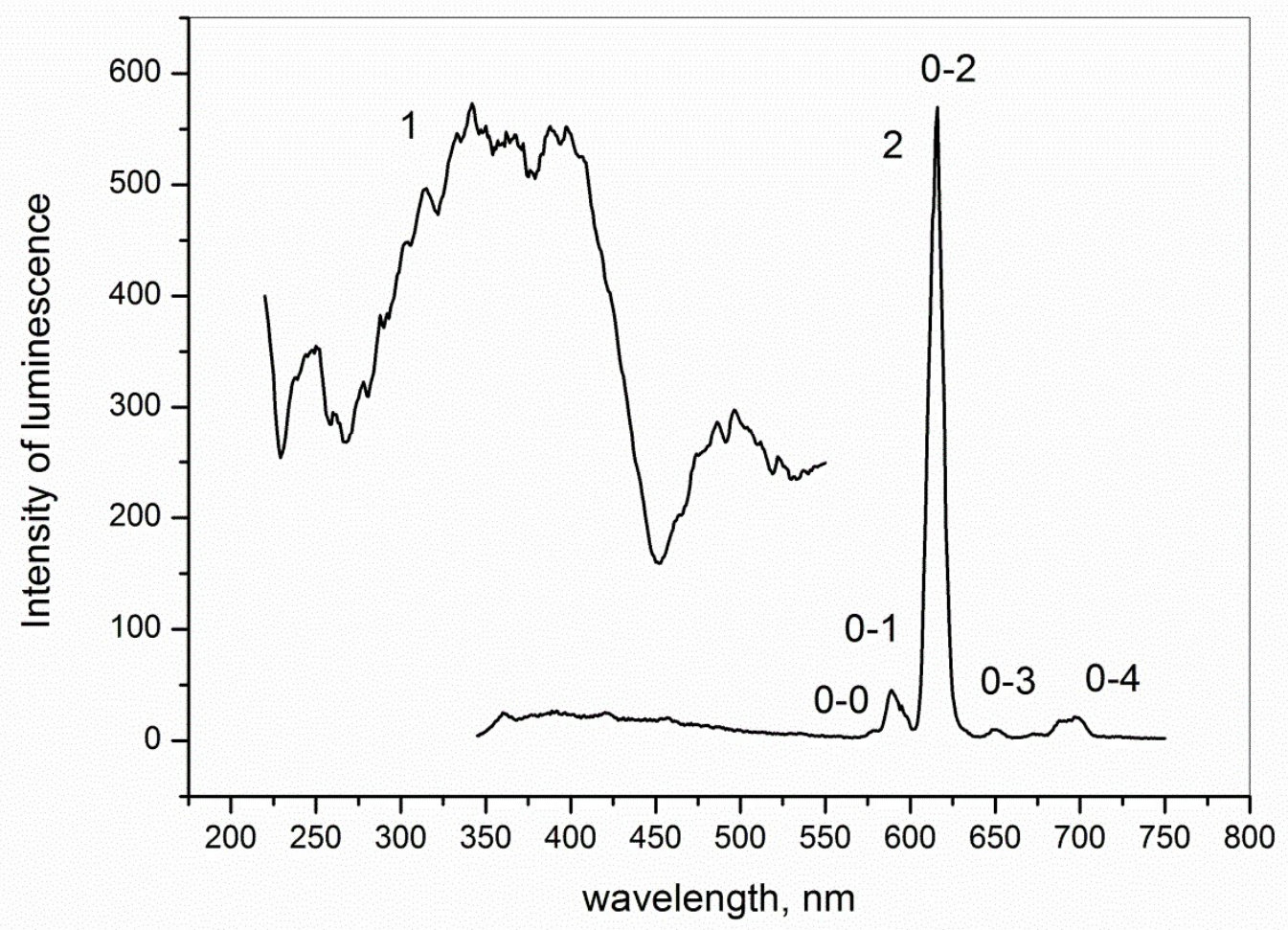

Figure 1. Luminescence (2) and excitation (1) spectra of $\mathrm{SiO}_{2}:\left[\mathrm{Eu}(\mathrm{ntac})_{3}\right][$ pphenden] micropowders, prepared using the method of physical adsorption of a $\left[\mathrm{Eu}(\mathrm{ntac})_{3}\right][\mathrm{pphenden}]$. The $\mathrm{Eu}^{3+}{ }^{5} \mathrm{D}_{0} \rightarrow{ }^{7} \mathrm{~F}_{\mathrm{j}}$ transitions are shown as $0-0,0-1,0-2,2-3$ and $0-4$.

In Fig. 2. a typical luminescence / excitation spectrum of $\mathrm{SiO}_{2}:\left[\mathrm{Eu}(\text { phen })_{2}\right]\left(\mathrm{NO}_{3}\right)_{3}$ powders produced from $\mathrm{SiO}_{2}: 0.05 \mathrm{Eu}^{3+}$ using adsorption of 1,10-phenanthroline (chemical functionalization) is presented. The relative intensity of the $\mathrm{Eu}^{3+}{ }^{5} \mathrm{D}_{0} \rightarrow{ }^{7} \mathrm{~F}_{2}$ transition is high, about $80-82 \%$ from the overall $\mathrm{Eu}^{3+}$ luminescence intensity between $570 \mathrm{~nm}$ and $750 \mathrm{~nm}$. It follows from second derivative luminescence spectra deconvolution, that the most probable symmetry of $\mathrm{Eu}^{3+}$ 
is $\mathrm{C}_{2 \mathrm{v}}$ [13]. Formation of $\left[\mathrm{Eu}(\mathrm{phen})_{2}\right]\left(\mathrm{NO}_{3}\right)_{3}$ as a result of the functionalization of silica and zirconia with 1,10-phenanthroline has been confirmed by X-Ray diffraction by comparing diffraction patterns of pure solid complexes and functionalized silica samples.

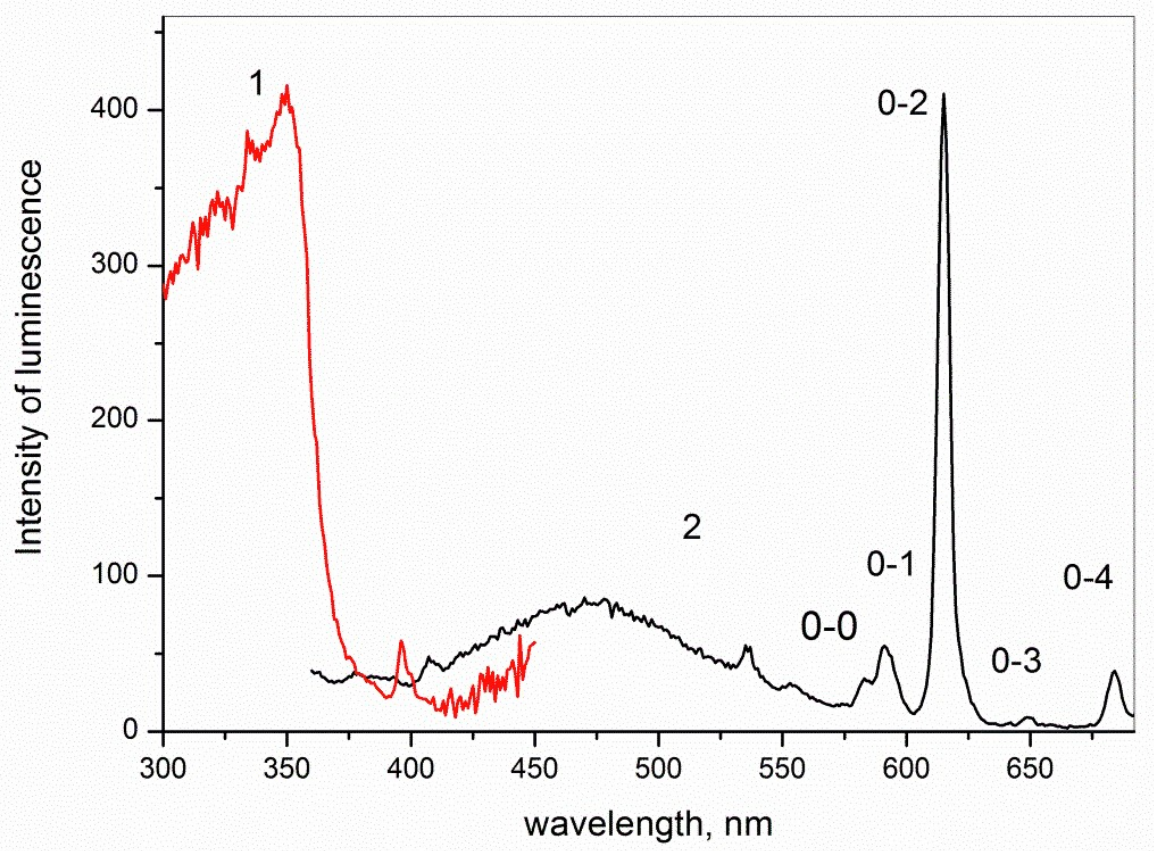

Figure 2. Typical luminescence (2) and excitation (1) spectra of $\mathrm{SiO}_{2}:\left[\mathrm{Eu}(\mathrm{phen})_{2}\right]\left(\mathrm{NO}_{3}\right)_{3}$ powders produced from $\mathrm{SiO}_{2}: 0.05 \mathrm{Eu}^{3+}$ functionalized using chemical adsorption of 1,10phenanthroline. The $\mathrm{Eu}^{3+}{ }^{5} \mathrm{D}_{0} \rightarrow{ }^{7} \mathrm{~F}_{\mathrm{j}}$ transitions are shown as 0-0, 0-1, 0-2, 2-3 and 0-4.

Figure 3. presents luminescence / excitation spectra of $\left.\mathrm{ZrO}_{2}: \mathrm{Eu}(\mathrm{phen})_{2}\right]\left(\mathrm{NO}_{3}\right)_{3}$ prepared using the method of doping with $\left.\mathrm{Eu}(\text { phen })_{2}\right]\left(\mathrm{NO}_{3}\right)_{3} \cdot \mathrm{nH}_{2} \mathrm{O}$ colloidal nanocrystals. The relative intensity of the color giving transition ${ }^{5} \mathrm{D}_{0} \rightarrow{ }^{7} \mathrm{~F}_{2}$ is about $80 \%$. The most probable activator symmetry is $\mathrm{C}_{2 \mathrm{~V}}$, confirmed by second derivative spectra analysis, shown in figure 4 . 


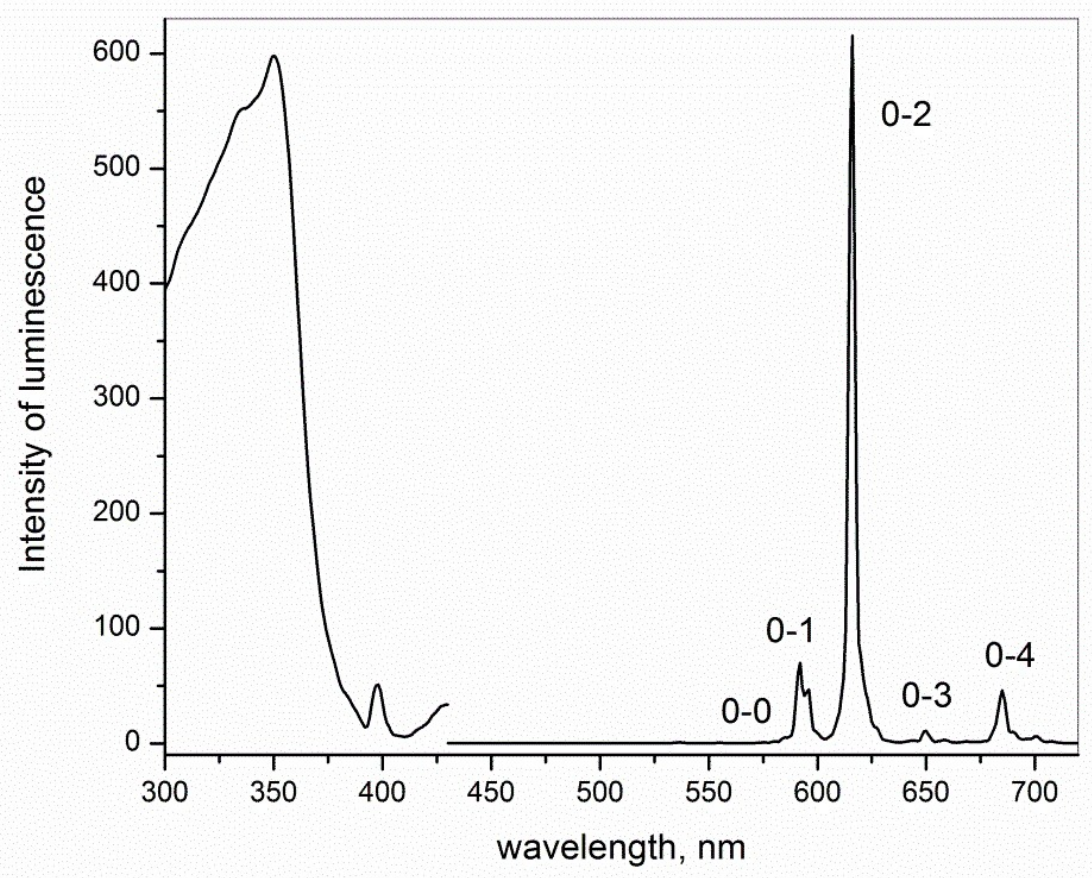

Figure 3. Luminescence (right) and excitation (left) spectra of $\mathrm{ZrO}_{2}$ : $\left.\mathrm{Eu}(\mathrm{phen})_{2}\right]_{\left(\mathrm{NO}_{3}\right)_{3}}$ prepared using the method of doping with $\left.\mathrm{Eu}(\mathrm{phen})_{2}\right]\left(\mathrm{NO}_{3}\right)_{3} \cdot \mathrm{nH}_{2} \mathrm{O}$ colloidal nanocrystals. The $\mathrm{Eu}^{3+}{ }^{5} \mathrm{D}_{0} \rightarrow{ }^{7} \mathrm{~F}_{\mathrm{j}}$ transitions are shown as $0-0,0-1,0-2,2-3$ and $0-4$. 


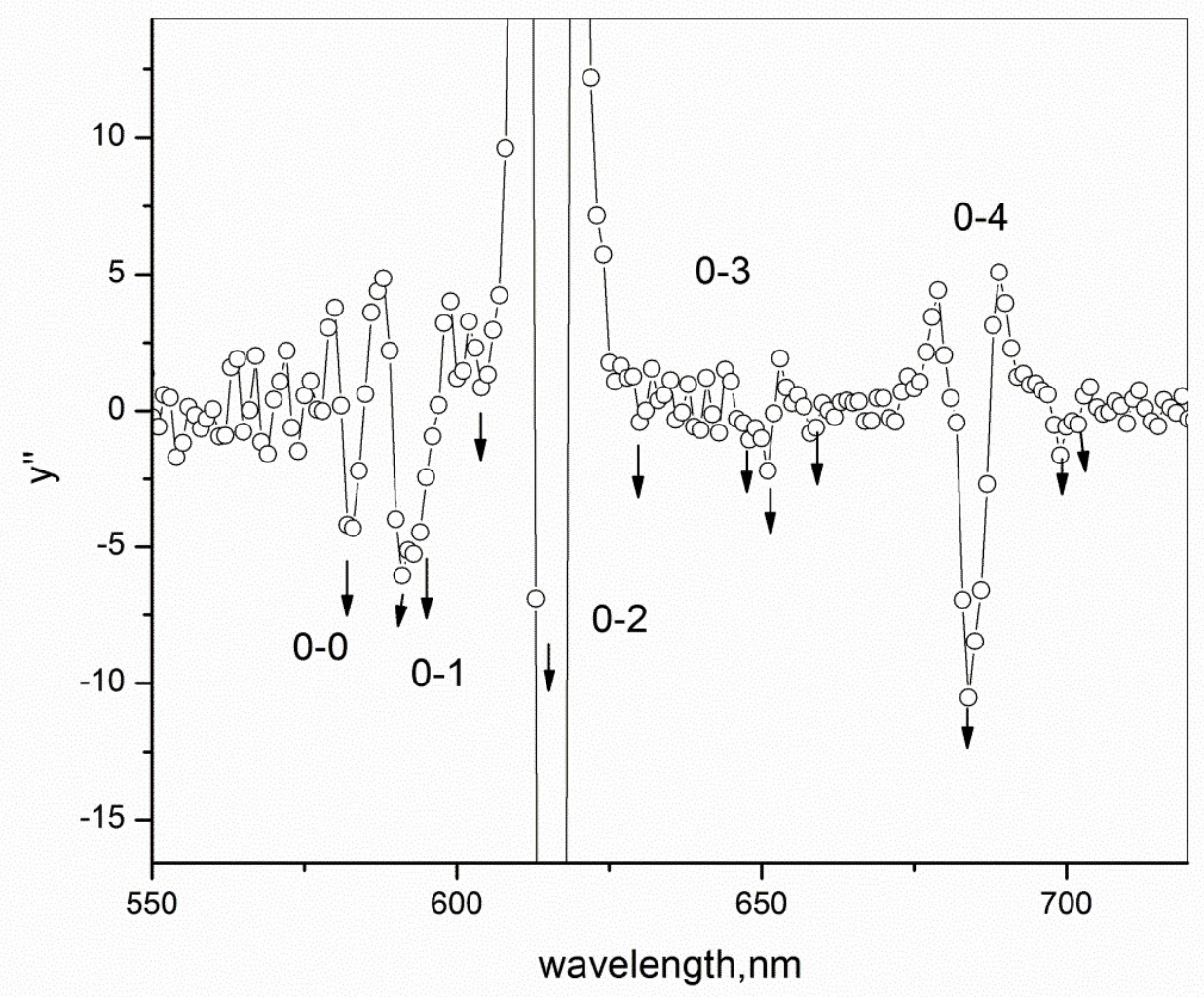

Figure 4. Second derivative luminescence spectra deconvolution of $\mathrm{ZrO}_{2}$ : $\left.\mathrm{Eu}(\text { phen })_{2}\right]\left(\mathrm{NO}_{3}\right)_{3}$, confirming the most probable site symmetry of the activator ion. The peaks in the region of each Stark multiplets are shown. The $\mathrm{Eu}^{3+}{ }^{5} \mathrm{D}_{0} \rightarrow{ }^{7} \mathrm{~F}_{\mathrm{j}}$ transitions are shown as 0-0, 0$1,0-2,2-3$ and $0-4$.

The luminescence emission of the prepared samples $\mathrm{SiO}_{2}:\left[\mathrm{Eu}(\mathrm{phen})_{2}\right]\left(\mathrm{NO}_{3}\right)_{3}$ $\mathrm{SiO}_{2}:\left[\mathrm{Eu}(\mathrm{ntac})_{3}\right][\mathrm{pphenden}]$ and $\left.\mathrm{ZrO}_{2}: \mathrm{Eu}(\text { phen })_{2}\right]\left(\mathrm{NO}_{3}\right)_{3}$ is very stable for long period of times (more than 1 year). The excitation spectra in figures 1-3 follow the absorption spectra of the organic ligands and unambiguously prove the occurrence of a very effective energy transfer in the prepared hybrid composites.

Table 1. presents the quantum yields of the investigated samples together with the doping level of the europium activator. In addition, the most probable site symmetry of the europium ion, extracted from the luminescence spectra, is given. The high quantum yields in table 1. confirm unambiguously that a ligand $\rightarrow$ europium charge transfer take place in all of the samples. The 
results in table 1. allow the potential application of the described hybrid powders as potential UV - sensors and label materials for chemical and biological applications.

Table 2 presents a quantification of the $\mathrm{Eu}^{3+}$ luminescence spectra, using three empirical parameters, described in our recent papers[6]. The parameter P1gives the intensity ratio between the integrated intensities of the electric - dipole transition $\mathrm{I}_{5 \mathrm{D} 0 \rightarrow 7 \mathrm{~F} 2}$ at $615 \mathrm{~nm}$ and the intensity of the magnetic dipole transition $\mathrm{I}_{5 \mathrm{D} 0 \rightarrow 7 \mathrm{~F} 1}$ at about $590 \mathrm{~nm}$ and the intensity. It is well known, that P1 is high in the case of non-centrosymmetric environment of $\mathrm{Eu}^{3+}$ [4-6].

$$
P_{1}=\frac{I_{5 D 0 \rightarrow 7 F 2}}{I_{5 D 0 \rightarrow 7 F 1}}
$$

The relative intensity of another $\mathrm{Eu}^{3+}$ transition, ${ }^{5} \mathrm{D}_{0} \rightarrow{ }^{7} \mathrm{~F}_{0}$ at $580 \mathrm{~nm}$ is also important in the $\mathrm{Eu}^{3+}$ spectra - structure correlation. It has been pointed out in the study of Binnemanns et al [13], that ${ }^{5} \mathrm{D}_{0} \rightarrow{ }^{7} \mathrm{~F}_{0}$ can be distinguished in the luminescence spectra only if europium ion has a site symmetry $\mathrm{C}_{2 \mathrm{v}}$ or lower. To describe more accurately the site symmetry in this study, the parameter P2 is expressed as follows: (2)

$$
P 2=\frac{I_{5 D 0 \rightarrow 7 F 0}}{I_{5 D 0 \rightarrow 7 F 1}}
$$

Here, $\mathrm{I}_{5 \mathrm{D} 0 \rightarrow 7 \mathrm{~F} 1}$ and $\mathrm{I}_{5 \mathrm{D} 0 \rightarrow 7 \mathrm{~F} 0}$ are the integrated intensities of the magnetic dipole transition ${ }^{5} \mathrm{D}_{0} \rightarrow{ }^{7} \mathrm{~F}_{1}$ at $590 \mathrm{~nm}$ and of the electric dipole ${ }^{5} \mathrm{D}_{0} \rightarrow{ }^{7} \mathrm{~F}_{0}$ transition at about $580 \mathrm{~nm}$. In table 2. the relative intensity of the ${ }^{5} \mathrm{D}_{0} \rightarrow{ }^{7} \mathrm{~F}_{2}$ transition also is given. It is well known, that europium doped optical materials for laser applications have a high relative intensity of the ${ }^{5} \mathrm{D}_{0} \rightarrow{ }^{7} \mathrm{~F}_{2}$ transition in the order of $70 \%[4]$. 


\begin{tabular}{|c|c|c|c|c|}
\hline Sample / Chemistry & $\begin{array}{c}\text { Excitation } \\
\text { [nm] }\end{array}$ & $\begin{array}{l}\text { QY } \\
{[\%]}\end{array}$ & $\begin{array}{l}\mathbf{E u} \\
{[\%]}\end{array}$ & $\begin{array}{l}\text { Site symmetry } \\
\text { of } \mathbf{E u}^{3+}\end{array}$ \\
\hline $\mathrm{SiO}_{2}:\left[\mathrm{Eu}(\mathrm{ntac})_{3}\right][$ pphenden $]$ & 400 & 17.4 & 0.1 & $\mathbf{D}_{2}$ \\
\hline $\mathrm{SiO}_{2}:\left[\mathrm{Eu}(\text { phen })_{2}\right]\left(\mathrm{NO}_{3}\right)_{3}$ & 352 & 39.6 & 5.4 & $\mathrm{C}_{2 \mathrm{~V}}$ \\
\hline $\mathrm{ZrO}_{2}:\left[\mathrm{Eu}(\text { phen })_{2}\right]\left(\mathrm{NO}_{3}\right)_{3}$ & 350 & 48 & 2.55 & $\mathrm{C}_{2 \mathrm{~V}}$ \\
\hline
\end{tabular}

Table 1. Excitation wavelengths, quantum yields (QY) and europium content of the investigated powdered samples at $615 \mathrm{~nm}$ emission wavelength. The most probable site symmetry of $\mathrm{Eu}^{3+}$ also is given.

Table 2 .

\begin{tabular}{|c|c|c|c|}
\hline Sample / Chemistry & $\begin{array}{c}\text { P1 } \\
-\end{array}$ & $\begin{array}{c}\mathbf{P 2} \\
-\end{array}$ & $\begin{array}{c}\text { Irel 5D0-7F2 } \\
\%\end{array}$ \\
\hline $\mathrm{SiO}_{2}:\left[\mathrm{Eu}(\mathrm{ntac})_{3}\right][$ pphenden $]$ & 8 & 0.03 & 82 \\
\hline $\mathrm{SiO}_{2}:\left[\mathrm{Eu}(\text { phen })_{2}\right]\left(\mathrm{NO}_{3}\right)_{3}$ & 8 & 0.29 & 83 \\
\hline $\mathrm{ZrO}_{2}:\left[\mathrm{Eu}(\text { phen })_{2}\right]\left(\mathrm{NO}_{3}\right)_{3}$ & 8 & 0.24 & 85 \\
\hline
\end{tabular}

Table 2. Quantification of $\mathrm{Eu}^{3+}$ luminescence spectra using three parameters: the intensity parameters $\mathrm{P} 1$ and $\mathrm{P} 2$ and the relative intensity of the color giving transition $\mathrm{I}_{\mathrm{rel}}$ 5D0-7F2 at $615 \mathrm{~nm}$. In the case of $\mathrm{SiO}_{2}:\left[\mathrm{Eu}(\mathrm{ntac})_{3}\right]\left[\right.$ pphenden] having $\mathrm{D}_{2}$ symmetry $\mathrm{P} 2$ is very low while in the case of $\mathrm{C}_{2} \mathrm{~V}$ symmetry $\left(\mathrm{SiO}_{2}:\left[\mathrm{Eu}(\text { phen })_{2}\right]\left(\mathrm{NO}_{3}\right)_{3}\right.$ and $\left.\mathrm{ZrO}_{2}:\left[\mathrm{Eu}(\text { phen })_{2}\right]\left(\mathrm{NO}_{3}\right)_{3}\right)$ the value of P2 is significant.

\section{Conclusions}

In this paper the functionalization of sol-gel silica and zirconia microparticles with $\left[\mathrm{Eu}(\text { ntac })_{3}\right][$ pphenden $]$ and $\left[\mathrm{Eu}(\text { phen })_{2}\right]\left(\mathrm{NO}_{3}\right)_{3}$ complexes using different physico-chemical techniques is described. New methods for functionalization, including chemical and physical adsorption and doping with colloidal nanocrystals for the preparation of hybrid composites are 
discussed. All the functionalized samples show a pure, stable in time red luminescence at UV excitation with quantum yield between $10 \%$ and $40 \%$ due to energy transfer from organic ligands to the $\mathrm{Eu}^{3+}$ ion. The site symmetry of the $\mathrm{Eu}^{3+}$ ion in the prepared hybrid composites is noncentrosymmetrical, $\mathrm{D}_{2}$ or $\mathrm{C}_{2 \mathrm{v}}$.

\section{Acknowledgment}

The authors thank M. Bredol and S. Stoyanov for luminescence spectra measurements. 


\section{References}

${ }^{1}$ Reisfeld, R., Optical materials, 16, 2001, 1-7

${ }^{2}$ Tanner, P., Yan, B., Zhang, H., Journal of Materials Science 35, 2000, 4325

${ }^{3}$ Chen, D., Yan, Y., Westengerg, E., Niebauer, D., Sakaitani , and. Chaudhuri, S., Journal of Sol-Gel Science and Technology 19, 2000, 77 - 82

${ }^{4}$ Blasse, G., Grabmaier, B., Luminescent materials, Springer, 1994

${ }^{5}$ Petkova, N., Dlugocz, S., Gutzov, S., J. Non Cryst. Solids, 357, 2011, 1547

${ }^{6}$ Petkova, N., Gutzov, S., Lesev, N., Kaloyanova, S., Stoyanov, S., Deligeorgiev, T. Optical Materials, 33, 2011, 1715

${ }^{7}$ Danchova, N., Gutzov, S., J Sol-Gel Sci Technol, 66, 2013, 248

${ }^{8}$ Danchova, N., Gutzov, S., Matras-Postolek, K., Bredol, M., Lesev, N., Kaloyanova, S., Deligeorgiev, T., Journal of Inclusion Phenomena and Macrocyclic Chemistry, 78, 2014, 381

${ }^{9}$ Danchova, N., Gutzov, S., Z. Naturforschung, 69b, 2014, 224

${ }^{10}$ Georgieva, I., Danchova, N., Gutzov, S., Trendafilova, N., J Mol Model, 18, 2011, 2409

${ }^{11}$ Mirochnik, A.G., Buktevskii, B.V., Zhikhareva, P.A., Karasev, W.E. Russian Chemical Bulletin Edition, 51, 2002, 1715

12 Gutzov S., Stoyanova P., Balashev K., Danchova N., Stoyanov S., Bulgarian Chemical Communications, $\mathbf{3}, 2015$, in press.

${ }^{13}$ Binnemans K., Görller-Walrand C, Journal of Rare Earths, 14 ,1996, 173 